\title{
LAS FIGURAS TEXTILES EN LA VESTIMENTA DE LOS MAYAS DE LA ÉPOCA PRECOLOMBINA
}

Chantal HuCKERT

Center for Archaeoastronomy

\section{Introducción}

Estudio aquí en los códices de Dresde y Madrid, junto con los glifos que los designan, los diseños textiles y las divinidades dedicadas a las artes de los hilos. No trato cada representación implicada en algún sector del quehacer textil, sino únicamente las que tengan interés por relacionarse directamente con los diseños. Éstos son pocos pero fundamentales, pues por ellos se establece una explicación satisfactoria para alguno de los diseños o figuras textiles de mayor difusión en la vestimenta del Clásico maya.

En ambos códices, una divinidad y su indumentaria, aguja, telar y la manta terminada o en proceso configuran la representación junto con glifos que nombran y dan cuenta de la actividad textil descrita. Al parecer las cosas serían sencillas, bastaría con mencionar los componentes, o sea una imagen, un glifo y una divinidad en flagrant délit trabajando en su telar o en la urdidera, por ejemplo. De hecho, la información es menos coherente o no está dispuesta según el modo lineal esperado. Por lo menos veremos juntos un telar autóctono de Mesoamérica y sin profundizar en el tema de las variantes entre estas divinidades, ni en el de su relación con la divinidad lunar, al leer para cada una su glifo nominal, pienso dejar en claro cuáles son las que dominan el campo textil en los dos documentos.

\section{El Códice de Dresde}

Quiero hacer una aclaración acerca de las fuentes mencionadas: en un principio recurrí al facsímil del Códice de Dresde publicado por J. An- 
tonio Villacorta. En la página 2e los glifos leíos pik ( $u$ pik) muestran rayas diagonales (figura 1a); sin embargo, luego de conocer la edición del facsímil de Ernst Förstemann, me di cuenta de que los glifos pic ( $u$ pik) son trazados con rayas diagonales y un punto en el centro de los rombos (figura 1b). Esta última es más cercana al original y es la que utilizo. $^{1}$

\subsection{El Glifo pik y la falda}

En D2e, imagen izquierda, la divinidad Ixik $^{2}$ sostiene una falda (figura 1c); el escrito dice $u$ ch'am "su ofrenda" $u$ pik "su falda": ${ }^{3}$ T1.625b:
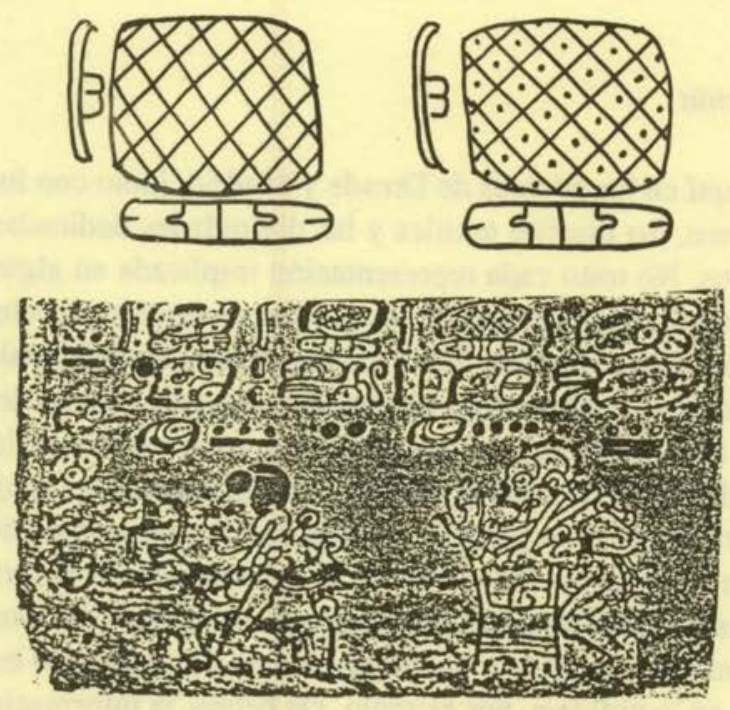

Figura 1. Las rayas diagonales con rombos, y los rectángulos repetidos en una faja en el borde de la prenda (dibujo mío). a: T1.625:102 u pik en el Códice de Dresde publicado por J. Antonio Villacorta C. y Carlos A. Villacorta, 1930. $b$ : u pik en el Códice de Dresde. c: D2e, Ixik sostiene su falda; el escrito señala: u pik 'su falda'

${ }^{1}$ Codex Dresdensis. Maya Handschrift Der Sächsischen Landesbibliothek, Dresde, 1962, Akademic, Verlag, Berlín. Codex Tro-Cortesianus Codex Madrid, vol. VIII de la serie Codices Selecti, 1967, Akademische Druk und, Verlagsanstalt, Graz. Códice de Dresde $=\mathrm{D} ;$ Códice Madrid $=\mathrm{M}$.

${ }^{2}$ Stephen Houston, Nikolaï Grube, 1995, comunicación personal.

3 James A. Fox y John S. Justeson, 1984; Polyvalence in Mayan Hieroglyphic Writing, John Justeson y Lyle Campbell, edits. Phoneticism in Mayan Hieroglyphic Writing, Publ. núm. 9, Institute for Mesoamerican Studies, State University of 
102; a su lado derecho el nombre del dios A seguido por un glifo de significado negativo relacionado con la muerte $e^{4}$ blandece una falda, la cual también viene designada como $u$ pik en el escrito. Como se ha dicho, pik es un cartucho cuya superficie es configurada por un enjambre de líneas cruzadas diagonalmente, a las que llamo rayas diagonales, y un punto en su centro. La falda misma es descrita en ambos casos con flecos y rectángulos reiterados en una franja que bordean la zona inferior de la prenda, los cuales el escribano y dibujante ha trazado de negro.

\subsection{U chuy 'costurar' $y$ la red}

En D2b, el dios R, la divinidad Chac Chel y el dios A costuran T1.857.62 u chuy, ${ }^{5}$ mientras pasa lo mismo en D2c, entre el dios del Maíz e Itzamná (figura 2a). Se observa que el objeto costurado es una red sostenida en un marco rectangular; parece tratarse de una bolsa (lo que me recuerda en México las bolsas en técnicas de red de Cuetzalan, de muchos diseños, las cuales se usan sostenidas por el mecapatl). El escrito no hace mención de la red, pero se conoce por ser el glifo T602, que se lee paw (la sílaba es $p a$ ), y se representa como rayas diagonales (figura 2b).

\section{El Códice Madrid}

\subsection{La trama de la tela: ochi(ya)}

En el Códice Madrid la lámina 79c enseña a la divinidad Chac Chel tejiendo (figura 3a); la urdimbre todavía sin trama denota que apenas empieza el proceso; el escrito dice "trama de la tela": T296.671 ochi (ya). ${ }^{6} \mathrm{~A}$ su lado el dios A se entrega a la misma actividad. En M102d (figura 3b) el escrito registra ochiya. $\mathrm{Na}^{\prime}$ Chel está fabricando la trama

New York, Albany, p. 35, apud J. Eric S. Thompson, 1972: 33, quien identific6 T625a, señalando su parecido con la imagen del caparazón de tortuga. N. Grube, M. Davoust, 1995, comunicación personal. Cordemex; 653: "naguas de las Indias que les sirven de saya o faldellín ordinario para cubrir desde la cintura aba'o".

${ }^{4}$ Nicolaï Grube, 1995, comunicación personal.

5 Ibidem. James A. Fox y John S. Justeson, 1984; Cordemex, 118: chuy 'coser o labrar o bordar en general'.

${ }^{6}$ Michel Davoust, 1995. L'écriture Maya et Son Déchiffrement, cNRs Ediciones, París, lámina 160 y comunicación personal. Cordemex, 594: o'och 'la trama de la tela'. 

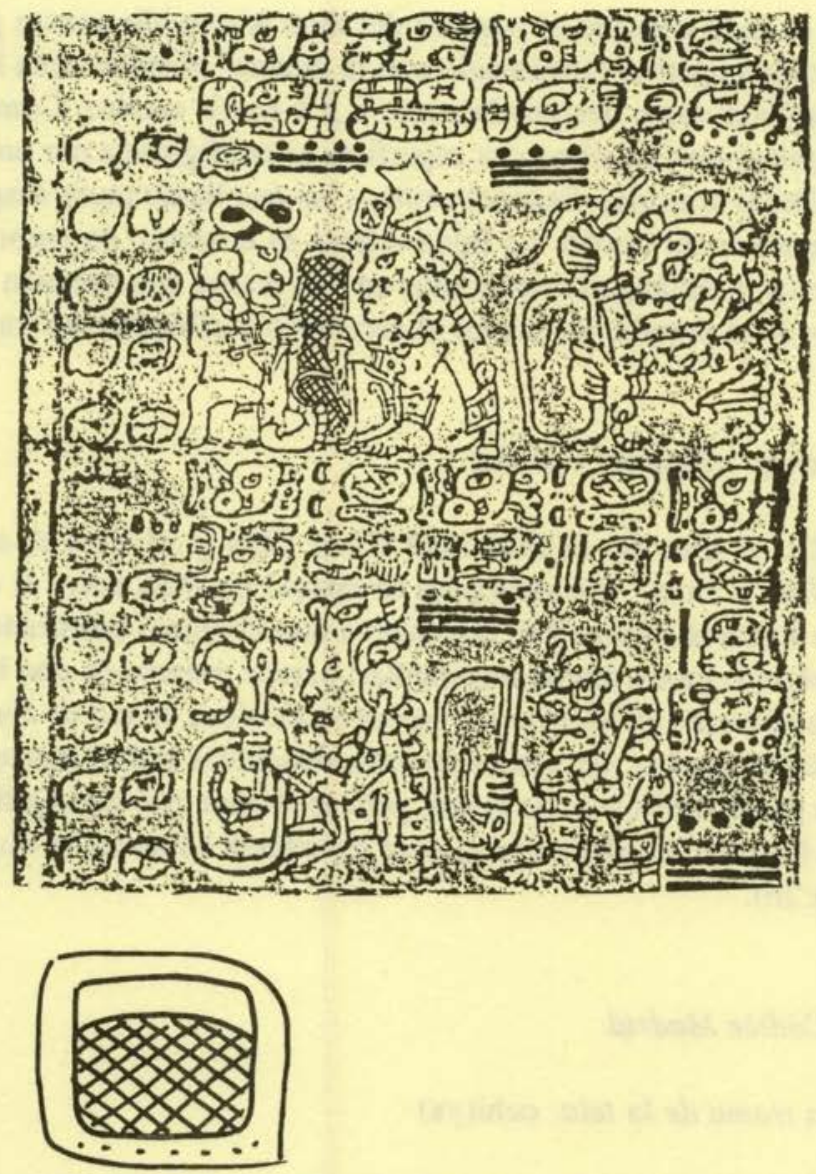

Figura 2. T1.857.82 u chuy 'costurar' y la red. $a$ : el dios R, la divinidad Chac Chel, el dios A, el dios del Maíz e Itzamná costuran, D2b y D2c; el escrito se lee $u$ chuy. b: T602 paw 'red' (dibujo mío)

de la tela, la cual en la representación aparece como un enjambre de hilos cruzados en diagonales. A la derecha se encuentra la divinidad Cizin Chel también elaborando su trama de tela.

\subsection{La tela tejido/las rayas diagonales}

Retomando el ejemplo de M102d observo que las rayas entrecruzadas simulan una trama; esto es una manera convencional de mostrarla. Sin embargo afirmo que también representa la tela cuando está terminada 

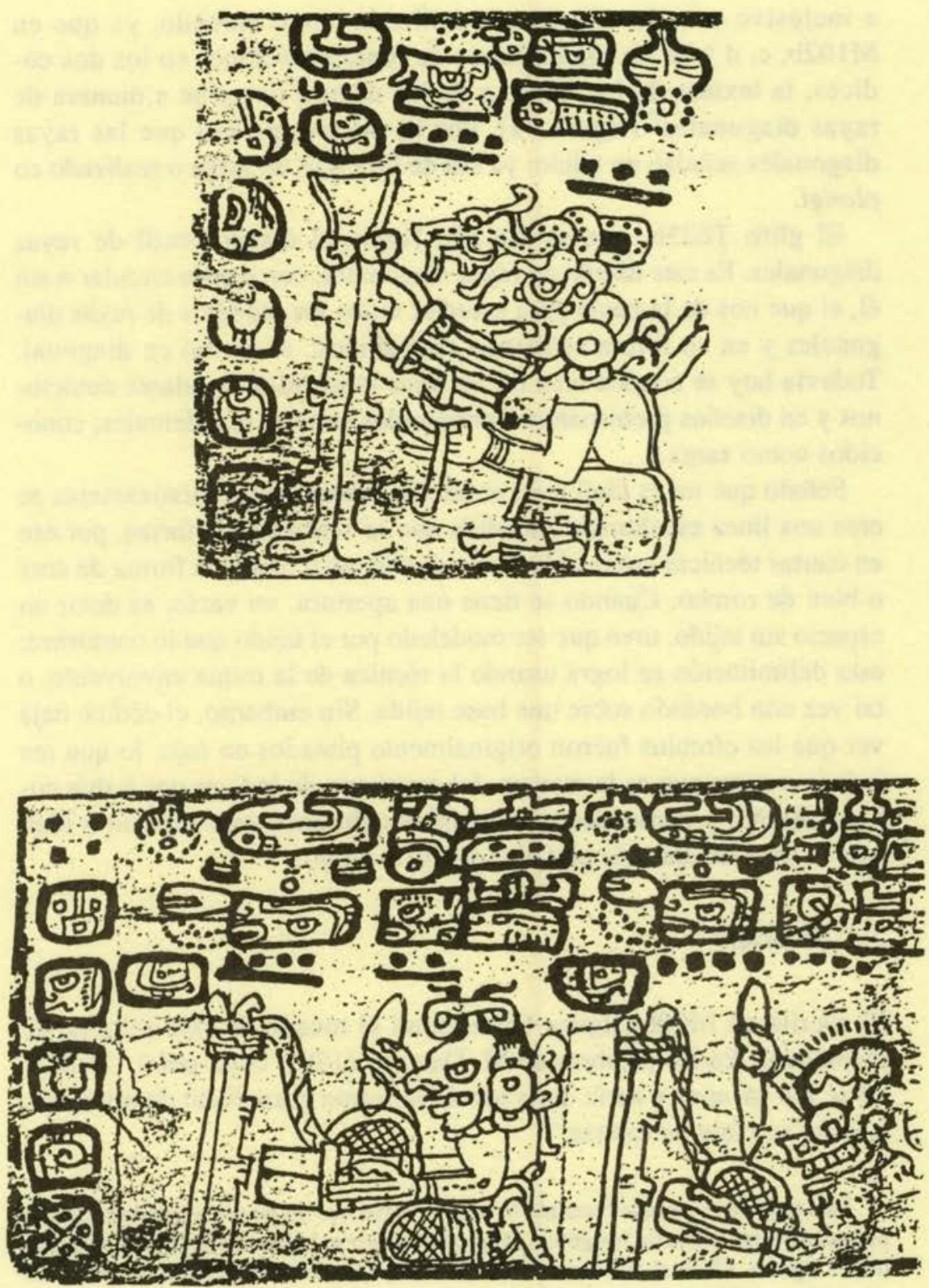

Figura 3. T296.671.47 o chiya 'la trama de la tela'. $a$ : Chac Chel y el dios A tejen; el escrito señala ochiya, M79c. $b$ : $\mathrm{Na}$ 'Chel y Cizin Chel elaboran su trama de tela, M102d 
e inclusive cuando está siendo utilizada como atuendo, ya que en M102b, c, d y en un gran número de representaciones en los dos códices, la textura de las faldas y de las mantas describe a manera de rayas diagonales ${ }^{7}$ (figura $4 a$ ). Por lo mismo, pienso que las rayas diagonales señalan un tejido: ya sea de brocado, de sarga o realizado en plangi.

El glifo T625b, que se lee pik, figura el diseño textil de rayas diagonales. Es este diseño de rayas diagonales, con centro circular o sin él, el que nos da la pauta para estudiar todos los modelos de rayas diagonales y en su forma estilística más abierta, el de red en diagonal. Todavía hoy se conoce bien en las telas fabricadas en telares autóctonos y en diseños prehispánicos producidos en telas occidentales, conocidos como sarga. ${ }^{8}$

Señalo que no es fácil tejer el círculo central, pues forzozamente se crea una línea escalonada a medida que se estructura la forma, por eso en ciertas técnicas como el brocado se obtiene o bien una forma de cruz o bien de rombo. Cuando se tiene una apertura, un vacío, es decir un espacio sin tejido, tuvo que ser modelado por el tejido que lo contornea; esta delimitación se logra usando la técnica de la trama envolvente, o tal vez con bordado sobre una base tejida. Sin embargo, el códice deja ver que los círculos fueron originalmente pintados en rojo, lo que me induce a creer que es la manera del escribano de indicar que había color y diseño, y consecuentemente hilos cubriendo este espacio o bien que se trata de una tela pintada (plangi o batik).

\subsection{El tocado}

El escrito en M90b (figura 4b) nombra el tocado de Ixik (ella no se menciona). En las palabras de M. Davoust (1995: com. pers) "T62EP: 23 se lee $y u-n(a)$, y sería derivado de la forma gramatical de posesión: u hum 'su cinta de cabeza"”.

${ }^{7}$ Mi tesis de doctorado concluía lo mismo, salvo que yo no tenía la evidencia que proporciona la lectura de los glifos. Mi razonamiento se basaba en la sola descripción de las figuras. Chantal Huckert, 1991, Constellations Textiles: La Leçon Maya, en microfilm en l'Ecole des Hautes Etudes en Sciences Sociales, París.

${ }^{8}$ El tejido llamado brocado permiete una modificación en el diseño; en cada pasada se aumenta o desplaza hacia los lados el par de hilos original (unidad mínima para poner color o crear tela); en tanto que la técnica de la sarga es fundamentalmente un movimiento de ampliar y restringir la unidad de hilos inicial para obtener figuras geométricas en zigzag o en diagonal (por lo tanto, también en rombo). 

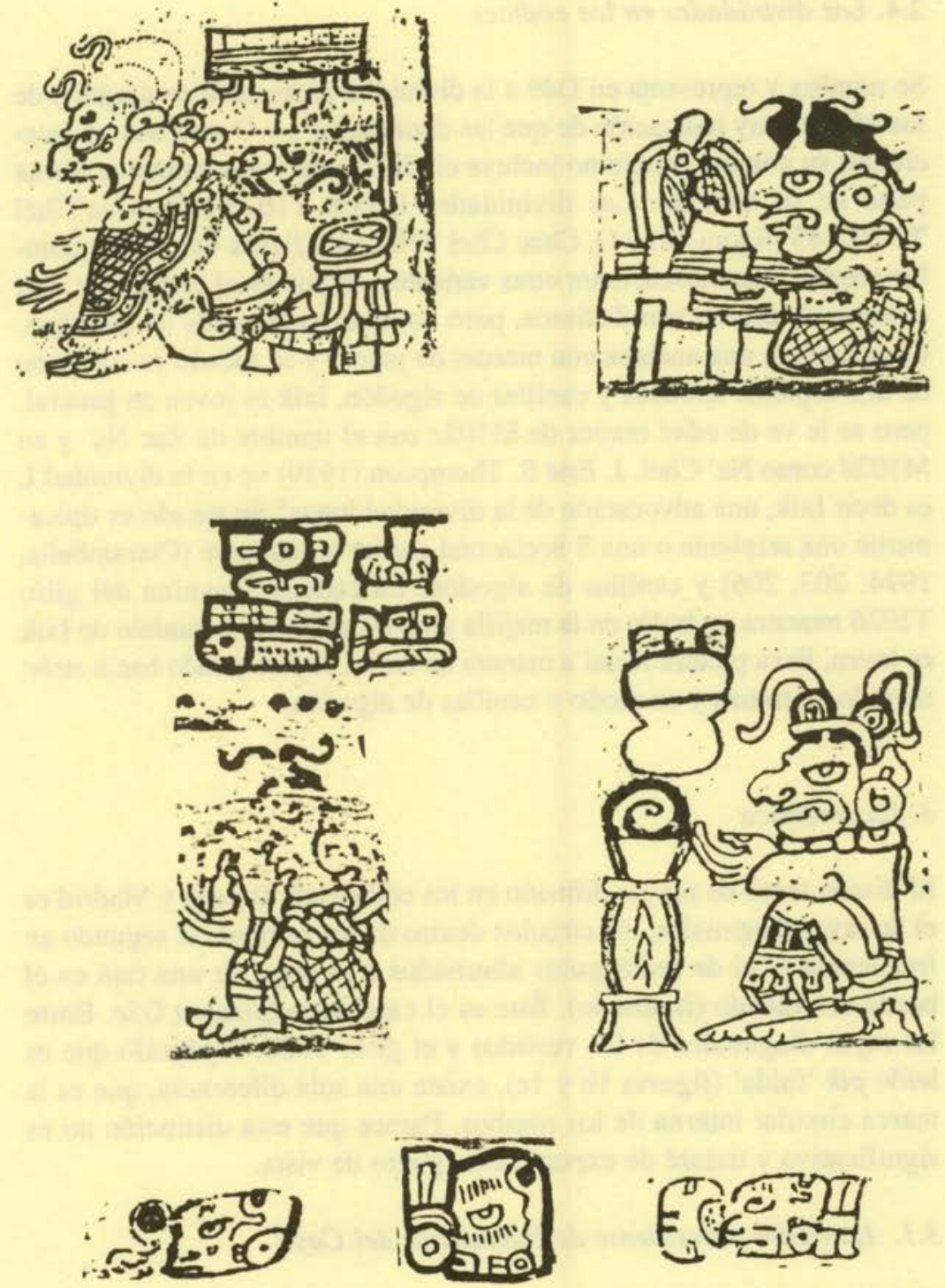

Figura 4. $a$ : las rayas diagonales como textura de la tela de los atuendos, D56b, M102c. b: T62EP:23 yuna 'su cinta de cabeza', M90b. $c$ : rectángulos alternados a lo largo del borde del vestido, M107b. $d$ : la divinidad I: T1026.102 Ixik, D2d, T1027.145 Na'Chel, M107b. $e$ : la divinidad O:T109.145 Chac Chel, D2b 


\subsection{Las divinidades en los códices}

Se nombra y representa en D49 a la divinidad lunar, pero en ninguno de los códices hay indicación de que las divinidades I y O sean sus advocaciones; su nombre propio no incluye el glifo lunar y éste tampoco forma parte de su atuendo. Las divinidades I, Ixik T1026.102 o Na'Chel T1027.145 (figura 4d) y O, Chac Chel T109.145 (figura 4e), tienen nombre propios fluctuantes; entre otras variantes, adquieren el prefijo zac. Sus campos de acción son distintos, pero comparten las artes de los hilos. Chac Chel es una anciana con marcas de jaguar y su tocado se compone de una sepiente anudada y canillas de algodón. Ixik es joven en general, pero se le ve de edad mayor de M102c con el nombre de Zac Na' y en M102d como Na' Chel. J. Eric S. Thompson (1939) ve en la divinidad I, es decir Ixik, una advocación de la divinidad lunar. ${ }^{9}$ Su tocado es típicamente una serpiente o una $\mathrm{S}$ horizontal que se le sustituye (Ciarambella, 1994: 203, 206) y canillas de algodón. La cabeza femenina del glifo T1026 muestra un bucle en la mejilla y en la cerámica el modelo de Ixik es joven, lleva pintura facial a manera de bucle, el pelo jalado hacia atrás, reunido en trenza y en moño y canillas de algodón.

\section{La cerámica}

El diseño textil de mayor difusión en los códices de Dresde y Madrid es el de rayas diagonales, sin círculos dentro de los rombos; el segundo en frecuencia es el de rectángulos alternados a lo largo de una faja en el borde del vestido (figura 4c). Éste es el caso de la falda en D2e. Entre las rayas diagonales de los vestidos y el glifo T625, logógrafo que es leído pik 'falda' (figuras 1 b y 1c), existe una sola diferencia, que es la marca circular interna de los rombos. Parece que esta distinción no es significativa y trataré de exponer este punto de vista.

\subsection{La vasija proveniente de Buenavista del Cayo}

A esta vasija le dieron el nombre de "Jarro Jauncy" los arqueólogos que la rescataron (Taschek y Ball, 1992). Fue encontrada en Buenavista del Cayo pero provenía de Naranjo (figura 5 a). El escrito registra la "pri-

9 J. E. S. Thompson, 1939, The Moon Goddess in Middle America with Notes on Related Deities, Contributions to America Anthropology and History, vol. v, núms. 24 a 29 , Carnegie Institution of Washington Publication núm. 509, Washington, D. C., pp. 162-163. 

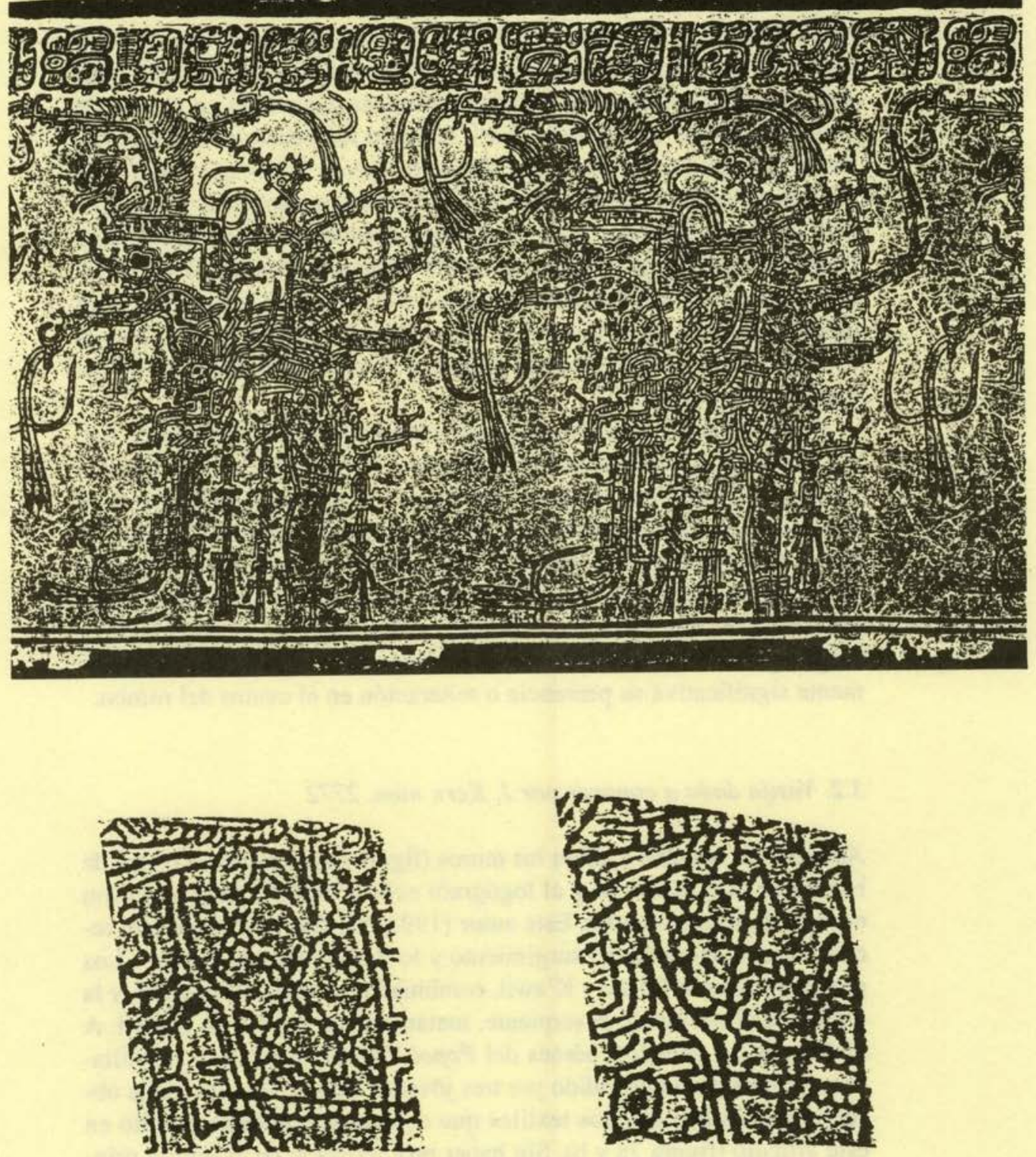

Figura 5. $a$ : vasija 4464 (J. Kerr, 1992). b: los rombos no traen una marca central. $c$ : los rombos traen una marca central 
mera secuencia patrón" y a continuación el nombre del soberano de Naranjo Butz' Tiliw (Grube et al., 1991). Esta vasija pone en escena a dos protagonistas identificados como los "danzantes de Holmul". El tema del "danzante" aparece en algunas cerámicas rescatadas en el sitio de Holmul y en sus alrededores. Karl Taube lo identificó como "dios del Maíz Tonsurado" (1985) y fue llamado "Joven Señor principal" por Nicholas Hellmuth (1987: 264). Cada uno de los danzantes encarna el dios del Maíz Hun Nal Ye, y su atuendo corresponde a esta identidad. Cada uno ostenta un artefacto dorsal de estructura idéntica, con la diferencia de que la entidad cawak 'tierra' o tal vez witz 'montaña', lleva un glifo distinto en su tocado, en uno el de la luna T683, en el otro el de Tikal, T569. Según Houston, Stuart y Taube (1992: 501-503), configura un topónimo.

El diseño del atuendo se presenta como pequeños elementos de forma cilíndrica, ensamblados en red diagonal (figura 5 b y c). Los rombos de los dos faldellines se distinguen por la presencia o ausencia de la marca circular. Sin ahondar aquí en la iconografía general, con base en que el tema preeminente es la encarnación del dios del Maíz Tonsurado por ambos danzantes, pienso que estos diseños son sustituibles. Otra posibilidad es que los mismos pequeños elementos de forma cilíndrica valgan por la marca circular, en cuyo caso no hubiera sido absolutamente significativa su presencia o reiteración en el centro del rombo.

\subsection{Vasija dada a conocer por J. Kerr, núm. 2772}

Abundan en el techo y sobre los muros (figura 6a) el signo en forma de bucle que es la sílaba uh y el logógrafo caban "tierra", alternando con espejos de forma circular. Este autor (1992: 55, fig. 3) incluye este recinto dentro del tema del surgimiento y lo llama "casa de espejo". Los protagonistas son Chaac y $\mathrm{K}$ ' awil, combinados en una sola entidad, y la divinidad $\mathrm{N}$ nacida de la serpiente, metamorfosis del pie de $\mathrm{K}$ 'awil. A la derecha los gemelos, héroes del Popol Vuh, se encuentran acuclillados, frente al trono presidido por tres jóvenes damas. En esta vasija observamos los tres diseños textiles que constituyen nuestro estudio en este artículo (figura 7a y b). Sin haber profundizado en el escrito principal ni en los rótulos secundarios, pienso que podrían aportar cierta información valiosa a la descripción iconográfica. Noto que el glifo de la divinidad lunar está en el escrito horizontal del registro superior (figura 6 b), a pesar de que no se trata de una "primera secuencia patrón". 
La primera dama o dama de adelante luce un vestido o huipil de rayas diagonales, lo mismo su compañera inmediata; solamente varían los rombos por los círculos interiores que adornan a cada uno. La tercera protagonista usa una falda distinta, que voy a estudiar más adelante detenidamente.

$\mathrm{El}$ atuendo de la primera dama incluye formas en S acostada y bucles alrededor del cuello del vestido, y constituye un diseño particular cuando bordea una circunferencia cuyo centro es circular (figura 7a). Se trata del signo muyal 'nube' o T632 (figura 7c). En M30 se asiste al momento en que la divinidad $\mathrm{O}$ riega agua, proyectándola desde sus hombros (Chaac figura sentado junto a ella). Su falda decorada de una especie de $\mathrm{S}$ acostada nos muestra los nubarrones que anuncian las lluvias (figura 7d). Esta joven no tiene ningún parecido con la divinidad O. Sin embargo, su vestido la relaciona con las nubes y lluvias benefactoras, y al respecto presenciamos la acción de Chaac/K'awil, quien detiene el relámpago.

No intentaré ahora ahondar en el simbolismo de la figura textil en la prenda de la segunda dama; sin embargo, vale señalar que los rombos con círculos concéntricos corresponden a la representación del caparazón de la tortuga, así como lo había notado Eric Thompson, y también a la hoja del lirio de agua: ambos, tortuga y lirio de agua, son poderosos elementos de la simbología maya prehispánica. El logógrafo que es leído pik 'falda', podría figurar a uno u otro. Ciertamente varias cerámicas ejemplifican a los gemelos Hunahpú e Xbalanqué del Popol Vuh con damas en el inframundo. En el texto quiché, su madre es Xquic, la hija de uno de los soberanos del inframundo. Ella es el prototipo del personaje femenimo, que realiza cosechas de maíz milagrosas. Posiblemente sea un aspecto de la divinidad lunar (Taube, 1992: 68; Tedlock, 1985: 328). En los relatos de Tonik Nibak, Robert Laughlin (1977: 165246) transcribe las fábulas de los tzotziles al respecto de la muchacha Relámpago y de sus abundantes cosechas de maíz; el antropólogo concluye estableciendo un paralelo entre Xquic y este personaje. ${ }^{10}$

Es frecuente en la iconografía un lirio de agua que desarrolla sus flores y hojas junto con pájaros o peces, y pertenece por excelencia al complejo de imágenes que participan del tema de la fertilidad acuática. El glifo del lirio de agua se puede leer naab 'extensión de agua' o ha 'agua'. Tratándose de flores, nos remite a ciertas divinidades aztecas, como Xochiquetzal.

${ }^{10}$ También Karl Taube (1992: 68) señala el paralelismo que R. Laughlin establece entre Xquic y la muchacha Relámpago. 

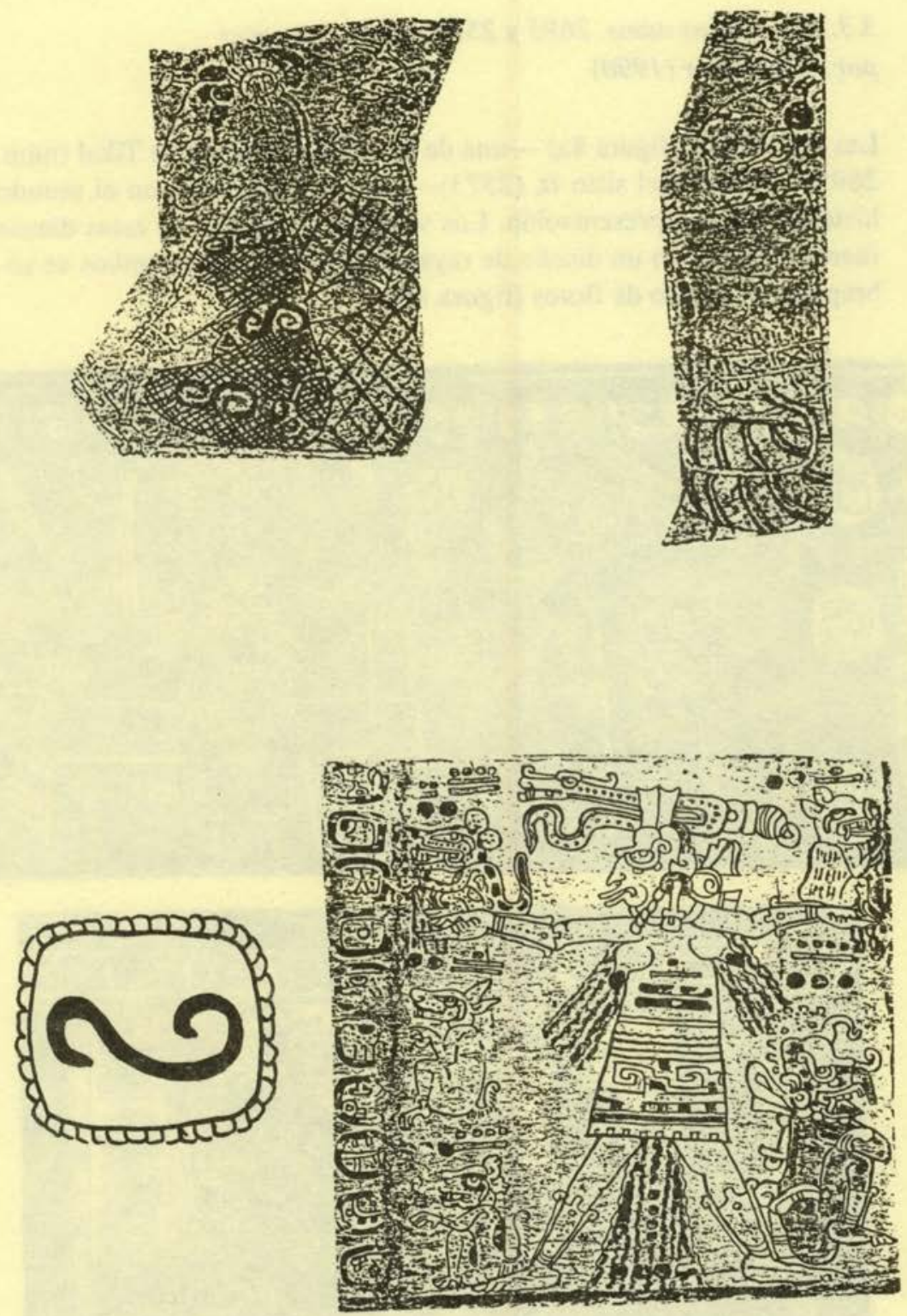

Figura 7. $a$ : la figura textil de rayas diagonales, uno con la representación del glifo T632 muyal 'nube'; el otro con la marca central en cada rombo, vasija 2772. $b$ : cintas paralelas que parten de un eje. $c$ : el glifo T 632 (dibujo mío). d: muyal 'nube' en la franja inferior del vestido de la divinidad O, M30 


\subsection{Las vasijas núms. 2695 y 2573 dadas a conocer por Justin Kerr (1990)}

Las dos vasijas (figura 8a) - una de las cuales procede de Tikal (núm. 2695) y la otra del sitio Ik (2573) - ya nos introducen en el mundo histórico de la representación. Los vestidos o huipiles de estas damas fueron tejidos con un diseño de rayas diagonales. A los rombos se sobrepone un diseño de flores (figura $8 b$ ).
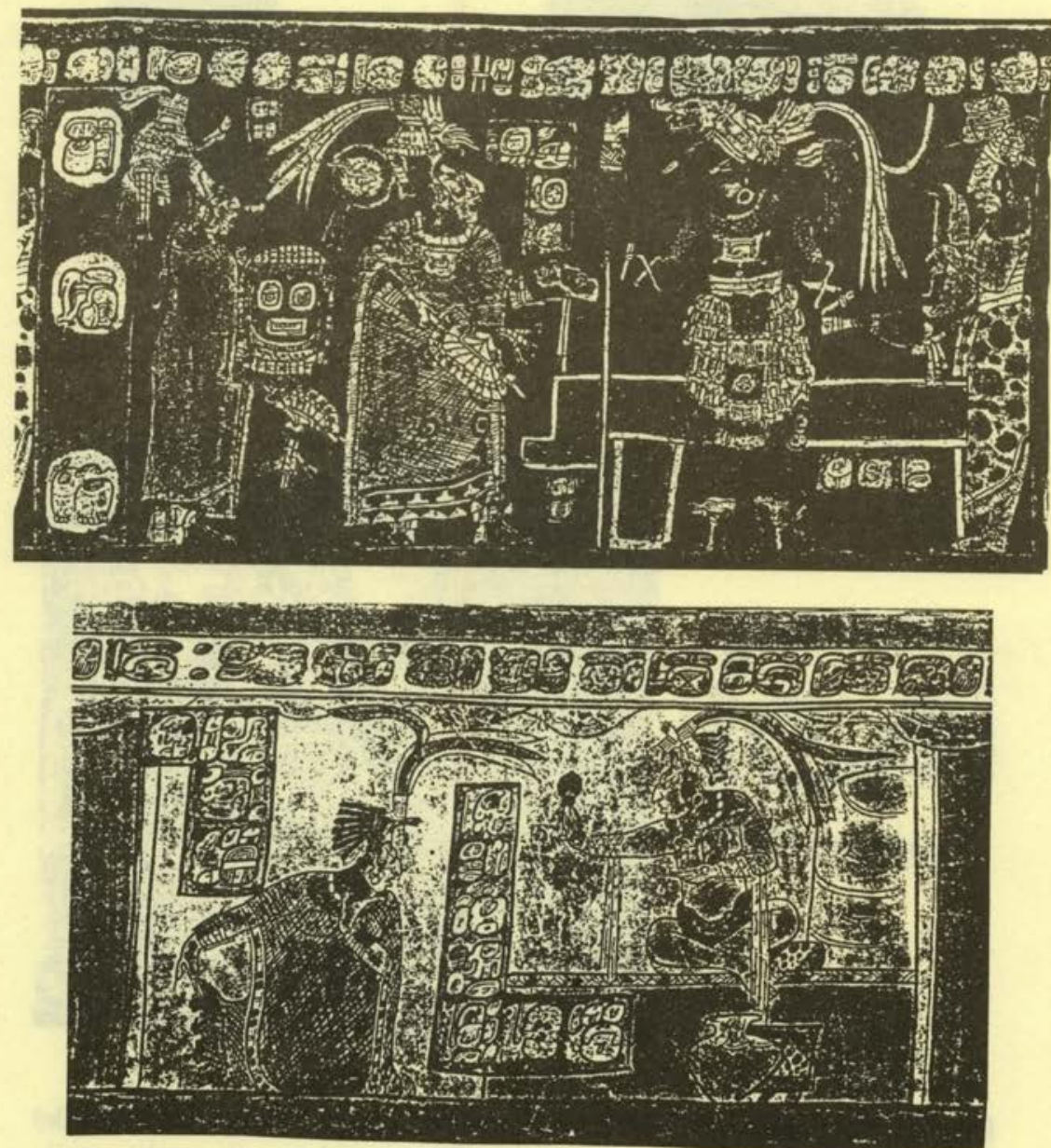

Figura 8. $a$ : las rayas diagonales a las cuales se sobrepone una figura textil floral, vasijas 2695, 2573 (Kerr, 1990) 


\subsection{La prenda con eje y cintas paralelas}

En la vasija anteriormente estudiada (figura $7 b$ ), la tercera dama viste una falda de enredos laterales, estrechamente pegada a su cuerpo: estos enredos se presentan en la forma de cintas que corren paralelamente.

En las vasijas 9 y 10 dadas a conocer por Francisco Robicsek y Donald Hales (1981), una dama de semblante y complexión parecida lleva la misma falda (figura 9 a y b). Existen varias vasijas con la misma temática, que comprende a esta joven alzada en los enroscamientos de la serpiente, metamorfosis del pie de $\mathrm{K}$ 'awil, y al dios $\mathrm{N}$, el cual surge de la boca del ofidio. El dios $\mathrm{N}$ es uno de los señores del inframundo, su forma de aparición típica es surgir de una concha. El escrito de la vasija 9 registra un nacimiento.

Esta falda se presenta como cintas laterales que parten de un eje o tronco grueso (figura 9d). La figura es idéntica al glifo T861a (figura 9c), el cual representa el agave, y es el logógrafo que se lee $K i$ 'agave' (Grube, 1991, cit. en Davoust, 1995: 610) (la sílaba es ki). Entre la falda y el glifo solamente varía el formato: en un caso se trata de una prenda que adapta el cuerpo femenino; en el otro de un glifo inserto en un cartucho. En la vasija 10 (figura 10a), la joven está apoyada en un lecho de hojas. El contorno es lanceolado, la punta es puntiaguda y parece una hoja espinosa. Opino que se trata de hojas de maguey. Existen otros ejemplos de ella recostada en este tipo de aposento, y de este último en contextos de sacrificio. T861a se lee $k i$ 'agave', por lo cual pienso que la falda puede formar parte del nombre propio de Ixik, compuesto por T102, descrito como 'hoja de maguey doblada' (Davoust, 1995: 560) y una cabeza femenina con rizo y el infijo IL en la mejilla, a la que he mencionado como T1026. A la vez, siendo Ixik divinidad protectora de los tejidos, no es extraño encontrar el maguey en su indumentaria, por ser planta proveedora de fibras para el tejido de ropas y para la fabricación de cuerdas. De las fibras del corazón se obtiene un tejido fino, y de las de las pencas, mantas más toscas y artículos como cuerdas y costales (El maguey..., 1988: 36-37; Guerrero, 1985: 66-70). Se señala la presencia de fibras identificadas cono agave entre los textiles encontrados en el cenote de Chichén Itzá. ${ }^{11}$ Este cáracter femeni-

"Silvia Terán (comunicación personal) me ha señalado la publicación de Gabriela García Lascuráin, Conservación de tejidos mayas procedentes del cenote. Véase también Joy Mahler Lothrop, 1992, "Textiles", en Artifacts from the Cenote of Sacrifices, Chichen Itza, Yucatan, Clemency Coggins, edit., Memoirs of the Peabody Museum of Archaelogy and Ethnology, Harvard University, vol. 10, núm. 3, pp. 36-37. 

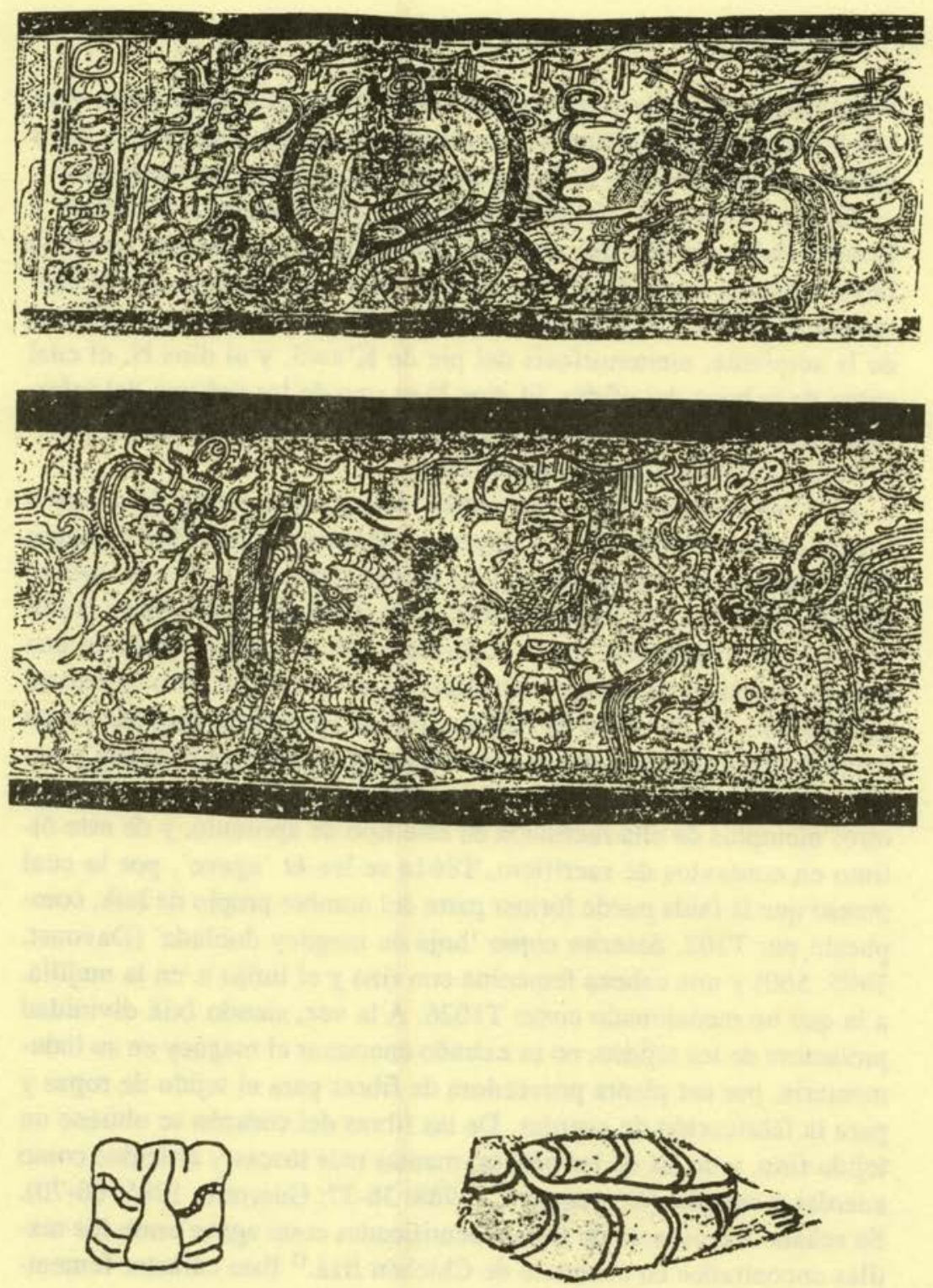

Figura 9. La representación del glifo T861a logógrafo del agave en forma de falda. $a$ : vasija 9 (Robicsek y Hales, 1981). $b$ : vasija 10. $c$ : T861a. $d$ : falda de cintas laterales que parten de un eje o tronco, vasija 10 , detalle 

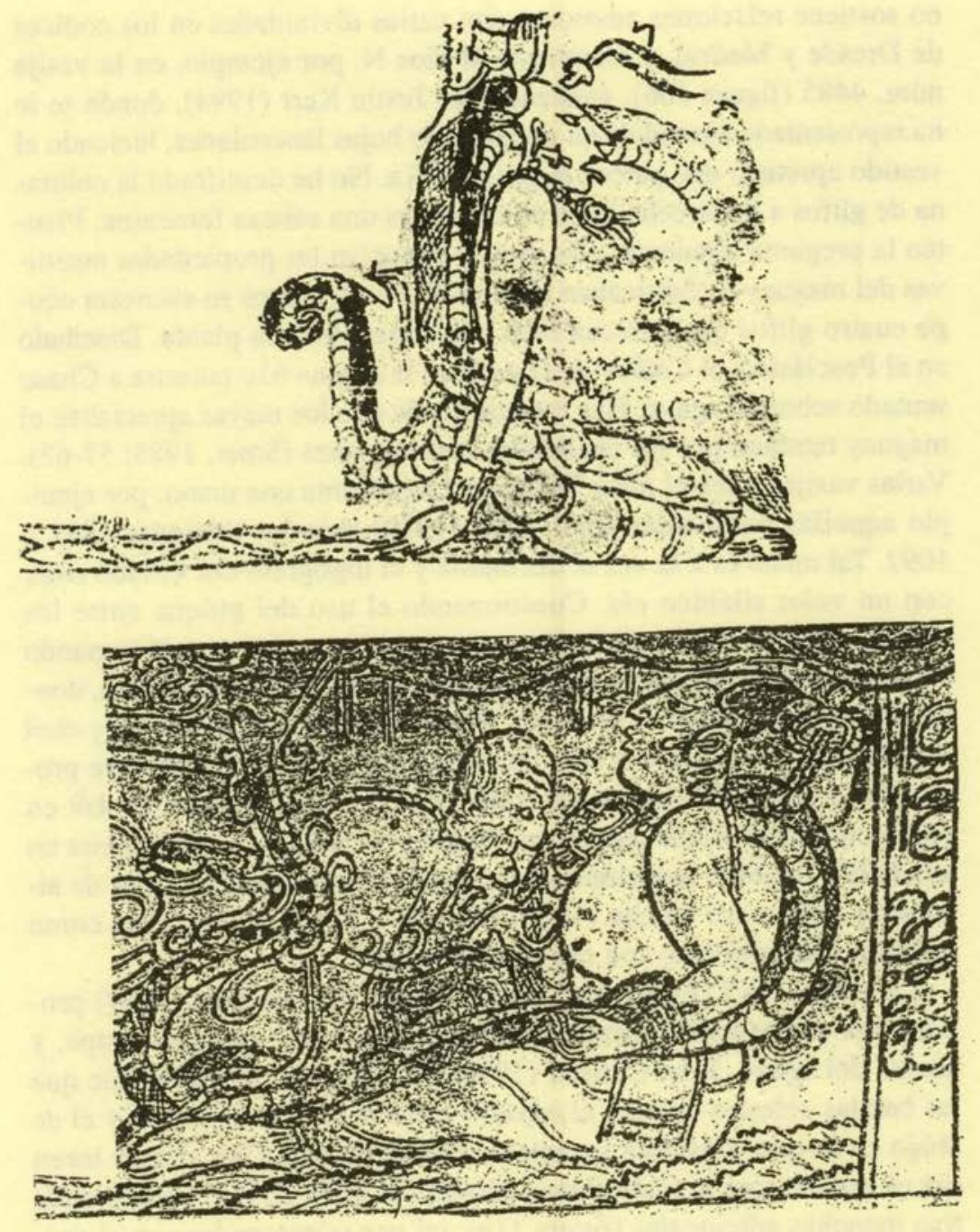

Figura 10. $a$ : la joven recostada en hojas espinosas, vasija 10. $b$ : la joven en su aposento de hojas espinosas y el dios $\mathrm{N}$; la cabeza femenina en el escrito, vasija 4485 (Kerr, 1994) 
no sostiene relaciones amorosas con varias divinidades en los códices de Dresde y Madrid, y amamanta al dios N, por ejemplo, en la vasija núm. 4485 (figura 10b), analizada por Justin Kerr (1994), donde se le ha representado extendida en un lecho de hojas lanceoladas, luciendo el vestido apretado que parece el glifo T861a. No he descifrado la columna de glifos a la derecha, pero el tercero es una cabeza femenina. Planteo la pregunta siguiente: ¿los mayas conocían las propiedades nutritivas del maguey?; ¿fabricaban aguamiel? Por lo menos su escritura ocupa cuatro glifos que parecen bien una penca, bien la planta. Diseñado en el Posclásico, el Códice de Dresde en la página 61c muestra a Chaac sentado sobre un agave. Hay evidencias de que los mayas apreciaban el maguey también por sus cualidades embriagantes (Smet, 1985: 57-62). Varias vasijas traen el glifo T671b que representa una mano: por ejemplo aquellas publicadas por J. Kerr (1989) bajo los números 1381 y 1092. Tal mano es a la vez el día manik y el logógrafo del venado chih, con un valor silábico chi. Cuestionando el uso del pulque entre los mayas, Peter de Smet señala las escenas en las cuales se está tomando o aun situaciones de embriaguez, además de los rituales de enema, donde se presenta el glifo de la mano. 'Venado' en las lenguas tzeltal y chol se dice chih y en yucateco keh. Peter de Smet (1989: 62) concluye proponiendo que chíh bien puede valer por cih en chol y tzeltal, kih en yucateco, términos que significan 'maguey' o 'delicioso, dulce (para un alcohol)'. También menciona que se producían diferentes clases de alcoholes aparte del balche (1989: 66, cita a Roys, 1943), y da como ejemplo uno fabricado con raíces de maguey.

La vasija 1485 (figura 11a) analizada por Justino Kerr (1989) proporciona aún mayor información acerca del diseño que nos ocupa, y acerca del agave. John Carlson (1988: 292-293, fig. 9.15) escribe que las bandas celestes dividen el espacio entre el mundo de arriba y el de abajo en lo que considera ser una escena de enema. Diez damas lucen ora el vestido, ora la falda, con el diseño del glifo T861a. Cada prenda trae manchas adicionales (figura $11 \mathrm{~b}$ ), tal vez relacionadas con el agave, pero hasta el momento sólo afirmaré que lo son aguellas redondas y como "peras pequeñas" (Gonçalves, 1956: 79; Herandi, lib. I. 258) que abundan pegadas a las cintas o ramas. Ya no aparece el eje; de hecho, la postura en cuclilla no lo permite, y no se aprecia tampoco por la toma de perfil, en el caso de la falda de la protagonista en posición vertical, al punto en que Itzamná la proyecta en el nivel inferior, o en el del vestido del par de damas corriendo junto a las vasijas de toda clase y uso, alineadas sobre dos filas en el piso frente a un trono. Gran núme- 

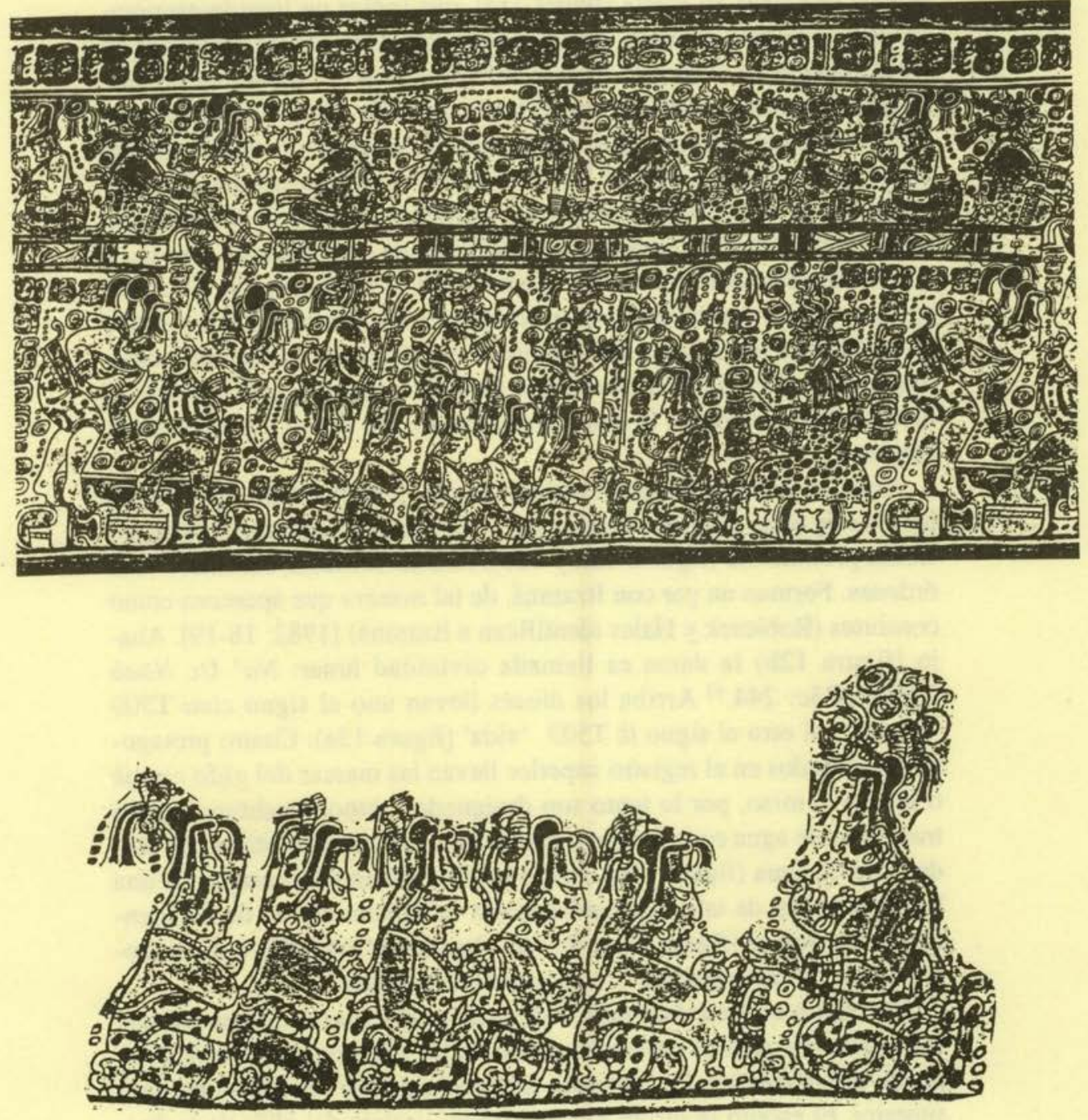

Figura 11. $a$ : vasija 1485 (Kerr, 1989). $b$ : las damas sentadas visten el modelo de la prenda con cintas paralelas decoradas de "peras pequeñas". $c$ : las vasijas 
ro de vasijas de varios tamaños forman parte de su indumentaria. En el segundo plano, uno de los recipientes se encuentra volteado de lado; lo bordea una línea en cresta (figura 11c), que indica un líquido espumoso. Éste y el jarro de junto, de pie, se parecen a las vasijas utilizadas en actos durante los cuales se ingiere bebida, o bien en rituales de enema. El que sigue, más pequeño, trae el bucle del glifo caban: $c a b$ (Davoust, 1995: 152), que designa 'la abeja, la miel la colmena y la tierra'. El que sigue es también del tipo de las vasijas que contienen bebida. Sin embargo, no es sistemática la relación vasija/ritual y aquí no hay seña alguna de tal situación; queda la posibilidad de un momento previo, o simplemente se describe a estas mujeres con su indumentaria. En cuanto a las vasijas semejentes por su temática a las números 9,10 y 4485 , que retratan a los mismos protagonistas, solamente la vasija 2067 estudiada por J. Kerr (1990) ofrece una alusión a algún brebaje, ya que el dios $\mathrm{N}$ alza una copa a la dama enredada en los enroscamientos de la serpiente.

Aquí las jóvenes llevan el mismo tocado, y una pintura facial similar. Dos de ellas ocupan visualmente y sin duda en importancia una posición prominente (figuras 12a y 12b). Ambas sentadas enseñan o dan órdenes. Forman un par con Itzamná, de tal manera que aparecen como consortes (Robicsek y Hales identifican a Itzamná) [1982: 18-19]. Abajo (figura 12b) la dama es llamada divinidad lunar: $N a^{\prime}$ Uc Naab T1000.683c: $244 .{ }^{12}$ Arriba los dioses llevan uno el signo cimi T509 'muerte', el otro el signo $i k$ T503 'vida' (figura 13a). Cuatro protagonistas sentados en el registro superior llevan las marcas del glifo cawak o tun en el torso, por lo tanto son designados como Pauahtunob, pero traen lirio de agua en la frente, y toman entonces características del dios del lirio de agua (figura 13b). Abajo los tres Pauahtunob cargan en una bandeja un par de telas adornadas según el mismo diseño de las prendas de las damas (figura 13c). Se ven claramente los tallos con las flores como "peras pequeñas", y las semillas pegadas.

No conozco el modelo mítico de esta representación. Observo que son varios los rótulos colocados junto de los personajes; su contenido puede ser revelador. La "primera secuencia patrón" ocupa el registro superior. El escrito se dirige a estas jovvenes usando del glifo de la divinidad lunar, y su ropa figura el logógrafo del agave, a su vez una imagen de la planta. Considero que las relaciones entre el dios N, Itzamná y ella (¿Ixik?: identidad que confirmaría la teoría según la cual Ixik es

${ }^{12}$ Ocupo el libro de M. Davoust (1995) para identificar los glifos. 

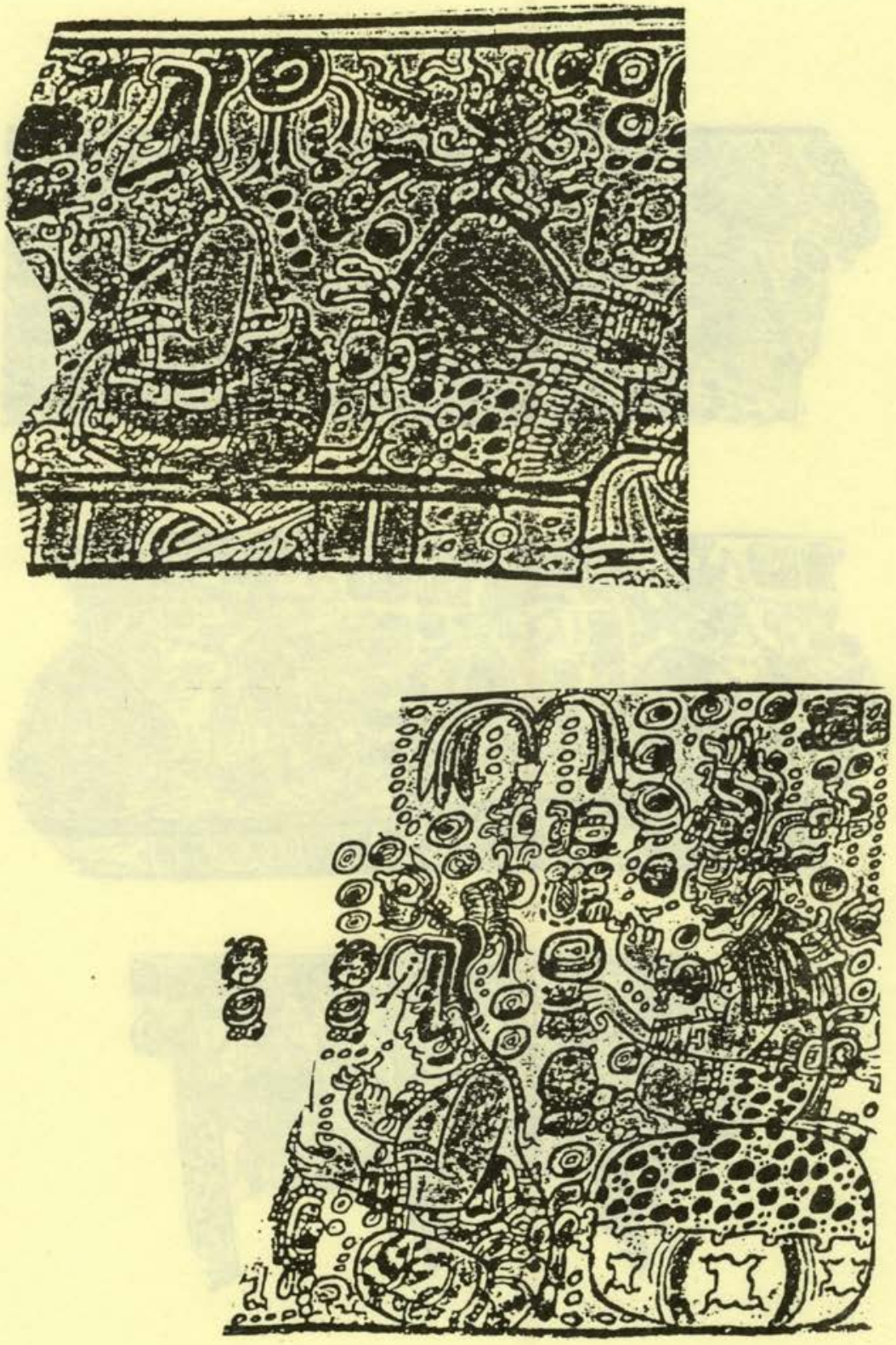

Figura 12. $a$ : junto con la figura $12 \mathrm{~b}$, ésta muestra a una dama sedente en una posición prominente, quien tiene por consorte a Itzamná. $b$ : esta dama es designada por el glifo lunar T1000.683. c: 244 , vasija 1485 , detalle 

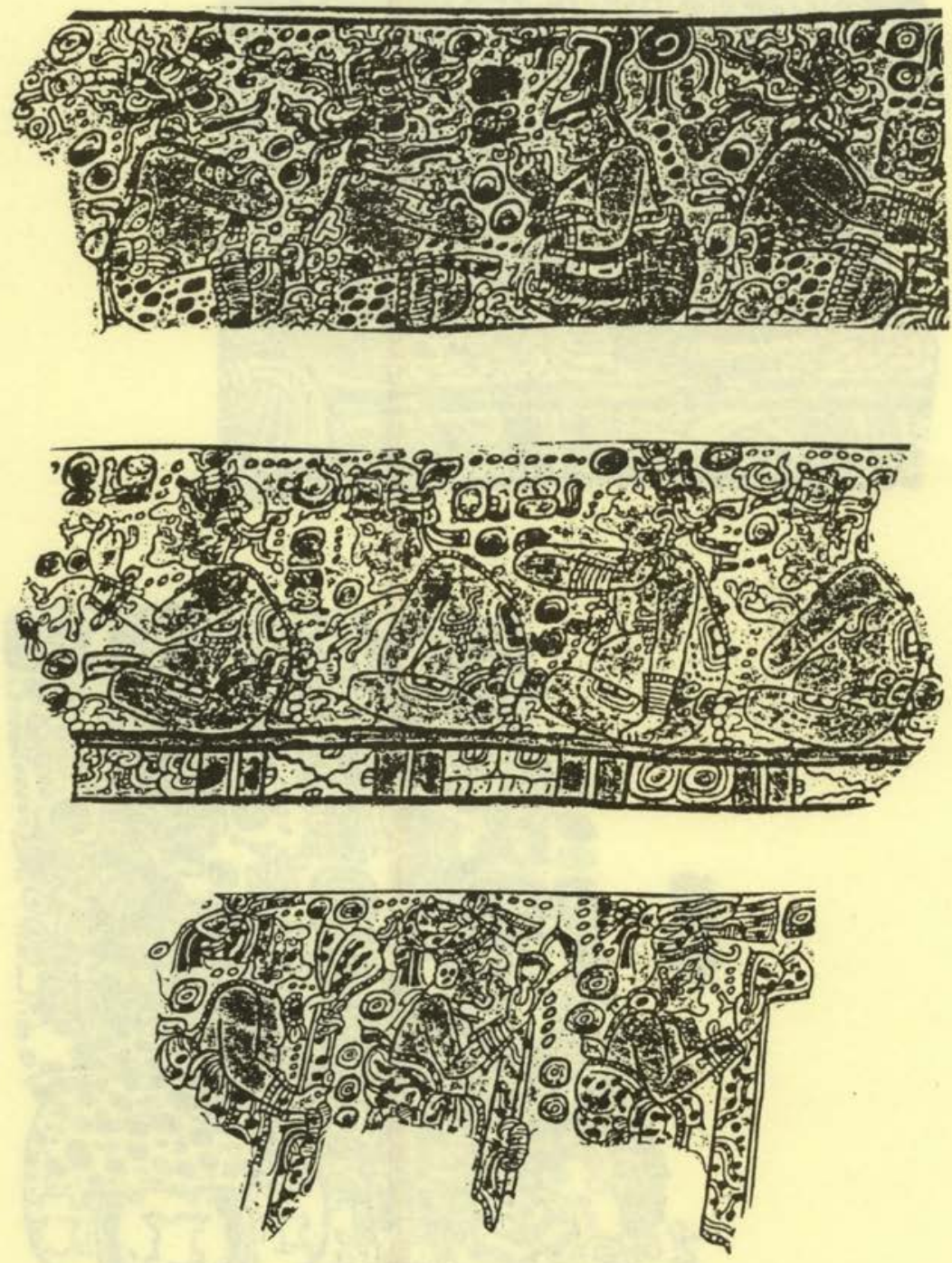

Figura 13. a: T509 "muerte", y T 503 "vida" señalan los dioses. $b$ : el lirio de agua en la frente de los Pauahtunob. $c$ : los Pauahtunob cargan un par de telas adornadas como las prendas de las damas, vasija 1485, detalle 
una de las manifestaciones lunares) en su aspecto de divinidad lunar, como individuos o como complejo, forman parte de una temática que incluye el agave.

\section{Conclusión}

El diseño de rayas diagonales es recurrente; se puede reunir un muestrario amplio al respecto. Establece en su modelo básico de rombos una textura textil que sirve de fondo a cierto número de figuras adicionales.

\section{Bibliografia}

CARLSON, John B.

1988 Skyband Representations in Classic Maya Vase Painting, Maya Iconography, Elizabeth P. Benson y Gillet G. Griffin, eds., University of Princeton Press.

Ciaramella, Mary A.

1994 The Lady with the Snake Headdress, Seventh Palenque Round Table, The Palenque Round Table Series, 1989, vol. 9, Merle Greene Robertson, ed. gral.; Virginia M. Fields, ed. de vol., The Precolumbian Art Research Institute, San Francisco.

\section{Códices:}

1962 Codex Dresdensis. Maya Handschrift Der Sächsischen Landesbibliothek, Dresde, Akademic Verlag, Berlín.

1967 Codex Tro-Cortesianus Codex Madrid, vol. VIII de la serie Codices Selecti, Akademische Druk und, Verlagsanstalt, Graz.

\section{Cordemex}

1980 Diccionario maya Cordemex, Alfredo Barrera Vásquez, Ediciones Cordemex, Mérida.

Fox, James A., y John S. Justeson

1984 Polyvalence in Mayan Hieroglyphic Writing, en John Justeson y Lyle Campbell, eds., Phonetism in Maya Hieroglyphic Writing, Pub. núm. 9, Institute for Mesoamerican Studies, State University of New York, Albany.

Davoust, Michel

1995 L'écriture Maya et Son D'échiffrement, cNRs Ediciones, París.

El maguey "árbol de las maravillas"

1988 Gobierno del estado de Hidalgo, Museo Nacional de Culturas Populares, pp. 36-37. 
Gonçalvez de lima, Oswaldo

1956 El maguey y el pulque en los códices mexicanos, Fondo de Cultura Económica, México; Hernandi, Francisci, De Historia Plantarum Novoe Hispanoe.

GUERRERo, Raúl

1985 El pulque, Instituto Nacional de Antropología e Historia, México.

GRUBE, Nicolaï, Linda Schele y Federico FAHSEN

1991 Odds and Ends from the Inscriptions at Quiragua, Mexicon, vol. XIII, núm. 6.

HeLLMUTH, Nicholas

1987 The Surface of the Underwaterworld: Iconography of the Gods of Early Classic Maya Art in Peten, Guatemala, vols. I y II, Foundation for Latin American Anthropological Research, vol. I.

Houston, Stephen, D., David Stuart y Karl TAUbe

1992 "Image and Text on the 'Jauncy Vase'", en J. Kerr, 1990 (1992).

HUCKERT, Chantal

1991 Constellations textiles: la Leçon Maya, tesis de doctorado, École des Hautes Études en Sciences Sociales, París.

KERR, Justin

1989- The Maya Vase Book, vols. 1-4, Kerr Associates Publ., Nueva 1994 York.

LAUGHLIN, Robert

1977 "Of Cabbages and Kings: Tales from Zinacantán”, en Smithsonian Contributions to Anthropolgy, núm. 23, Smithsonian Institution Press, Washington, pp. 165-246.

MAHLER LOTHROP, Joy

1992 "Textiles", en Clemency Coggins (edit.), Artifacts from the Cenote of Sacrifice, Chichen Itza, Yucatan, Memoirs of the Peabody Museum of Archaeology and Ethnology, Harvard University, vol. 10, núm. 3.

RoBicseK, Francis, y Donald Hales

1981 The Maya Book of the Dead. The Ceramic Codex: The Corpus of Codex Style Creamics of the Late Classic Period, University of Oklahoma Press, Norman, Oklahoma.

1982 Vases from the Late Classic Period, The November Collection of Maya Ceramics, U. Museum of Virginia, Charlottesville, Virginia.

SMET, Peter A. G. M. de

1985 "Ritual Enemas and Snuffs in the Americas", en Latin America Studies, núm. 33, CEDLA, Holanda. 
TASCHEK, Jennifer T., y Joseph W. BALL

1992 "Lord Smoke Squirrel's Cacao Cup: The Archaeological Context and Socio-Historical Sgnificance of the Buenavista 'Jauncy Vase"', en Justin Kerr, The Maya Vase Book, vol. 3, Kerr Associates Publ., Nueva York.

TAUBE, Karl

1985 The Classic Maya Maize God: A Reappraisal, Fifth Palenque Round Table, 1983, vol. VII, Merle Greene Robertson, ed. gral.; Virginia Fields, ed. de vol., The Precolumbian Art Research Institute, San Francisco, pp. 171-181.

1992 The Temple of Quetzalcoatl and the Cult of Sacred War at Teotihuacan, Res 21.

1992 The Major Gods of Ancient Yucatan, Studies in Pre-Columbian Art \& Archaelogy, núm. 32, Dumbarton Oaks Research Library and Collection, Washington, D. C.

Thompson, J. Eric S.

1939 The Moon Goddess in Middle America with Notes on Related Deities, Contributions to America Anthropology and History, vol. v, núms. 24 a 29, Carnegie Institution of Washington Publication 509, Washington, D. C. 